\title{
Is 2D Fluoroscopy Reliable in Minimal Invasive Spine Surgery? Evaluation of Perforation Indices in MIS-TLIF
}

\author{
Mohit Kumar Meena, Vishal G Kundnani, Ankit Patel, Sanyam Jain, Jwalant Y Patel, Saijyot Raut \\ Department of Orthopaedics, Bombay Hospital and Medical Research Center, Mumbai, India
}

Corresponding Author:

Mohit Kumar Meena, MD, MS

Department of Orthopaedics, Bombay

Hospital and Medical Research Center, 12, New Marine Lines, Mumbai-400020, Maharashtra, India

Tel: $+91-022-22067676$

Fax: +91-022-22067676

E-mail: dr.82mohit@gmail.com

Received: May 10, 2020

Revised: July 12, 2020

Accepted: August 9, 2020
Objective: The aim of this study is to assess reliability of 2D Fluoroscopy in Minimal Invasive Surgery Transforaminal Lumbar Interbody Fusion (MIS-TLIF) through evaluation of perforation indices in 1,200 percutaneous pedicle screw instrumentation. Methods: It is a single center retrospective study of 300 consecutive patients undergoing single level minimal invasive lumbar interbody fusion surgery (MIS-TLIF) under 2D Fluoroscopy. Percutaneous pedicle screws were analyzed with post-operative CT scan to assess accuracy of pedicle screw placement, Grades of perforation, Critical vs. Non critical Nature, Location of violation. Neurological implications of misplaced screws, Demographic, Clinical Parameters, outcome scores viz. Visual Analogue Score (VAS), Oswestry Disability Index (ODI) were also assessed. Results: Overall rate of screw perforation was $5 \%(60 / 1,200)$ with different grades of perforation(Medial=24, Lateral $=30$, Inferior $=1$, Superior $=5$, Anterior $=0$ ) (Grade 1=42, Grade 2=18, Grade 3=0). Critical perforations were noted in 18 patient but none of the patients with critical and non critical perforation developed any neurological complications or post-operative leg pain. Conclusion: This study showed overall pedicle perforation rate of $5 \%(60 / 1,200)$ in lower lumbar single level MIS-TLIF for grade 1 degenerative spondylolisthesis including grade 1 perforations are $3.5 \%$ and grade 2 perforation are 1.5\%. 2D Fluoroscopy guided percutaneous pedicle screws placement with appropriate technique in MIS-TLIF is an acceptable and reliable procedure with low rates of screw related complications and revisions.

Key Words: Critical perforations, Degenerative lumbar disease, Minimally invasive surgery (MIS), Pedicle screws, Transforaminal lumbar interbody fusion

\section{INTRODUCTION}

Advances in minimally invasive spinal surgery (MISS) are changing the ways operative treatment approaches of spinal disorders. Since the development of tubular retractors facilitating a microsurgical decompression of spinal degenerative pathology, MIS has evolved to permit placement of instrumentation percutaneously or through mini open approaches, ${ }^{8,2030}$. These techniques may show improved outcomes and reduced complications, such as a reduction of persistent back problems caused by muscular atrophy and decreased trunk extensor strength from iatrogenic muscle denervation ${ }^{5,9,12,13,27,31)}$. Application of transpedicular screws for spinal instability had undergone technique refinements pursuing 100\% accuracy. Pedicle screw fixation is a wellknown and safe technique for spine surgeons with a low rate of complications however risk of serious neurological lesions, cerebrospinal fluid leaks, vascular and visceral injuries have raised interest to evaluate safety and accuracy for pedicle screw placement. Transforaminal lumbar interbody fusion (TLIF) is one of the most commonly performed lumbar fusion procedures. Evolved from a posterior lumbar interbody fusion approach, it allows an anterior fusion through a unilateral posterior approach while avoiding the risks associated with excessive Dural sac retraction, bilateral posterior lumbar dissection and graft placement ${ }^{11)}$. Accurate pedicle screw placement using MIS techniques requires significant learning curve in the operative technique due to lack of direct visibility of correct entry point like in open surgery and relies on tactile feedback of surgeon and intraoperative fluoroscopy with sequential biplanar imaging. Studies performing evaluation of perforation indices in percutaneous pedicle screws instrumentation in MIS-TLIF are scanty. 
The objective of this study was to evaluate the radiographic accuracy of 2D fluoroscopy guided percutaneous technique for pedicle screw placement in MIS-TLF procedure for the lumbar spine. Bridging the gap between comprehensive understandings of the factors involved in pedicle screw perforation and their clinical correlation is a critical component in avoiding revision surgery and to deal with the complications associated with that surgery. This study aimed to assess the perforation indices of pedicle screw in MIS-TLF and to elucidate the factors influencing perforation incidence.

\section{MATERIALS AND METHOD}

This retrospective radiological observational study analysed 300 consecutive single level lower lumbar MIS-TLIF cases (1,200 screws). The study was reviewed and approved by the Human Ethics Committee of the Bombay Hospital and Medical Research Centre (IRB approval no. 182/12/2019). Informed consent was taken from all individual participants included in this study. In total, 300 patients who underwent single level MIS-TLIF from June 2012 to June 2017 were included with a minimum follow up of 24 months. As all patients had screws placed bilaterally, this study has evaluated a total of 1200 screws. Inclusion criteria were as follows: (1) single level lumbar or lumbosacral symptomatic degenerative spondylolisthesis grade 1 (Fig. 1(A)) and (2) failed conservative trial of 3 months. Exclusion criteria were as follows: (1) Multilevel spinal instability (2) Previous spinal surgery (3) Spinal trauma or infection, and (4) deformity. The surgical decision to undergo MIS-TLIF was based on patient preference for MIS and thorough clinical and radiological evaluation including preoperative X-ray, CT scan and MRI. All surgeries were performed by a single experienced surgeon at single centre using and maintaining the same perioperative protocols.

\section{Surgical Procedure}

Under general anesthesia and prone position, Anteroposterior (AP) and lateral fluoroscopic images are obtained and the vertebrae to be instrumented are marked with the 2D fluoroscopy. Patients who underwent MIS-TLIF had screws placed through paramedian incisions approximately $2 \mathrm{~cm}$ long and $3-5 \mathrm{~cm}$ lateral to the midline at appropriate level (Fig. 1B). We used a more lateral incision lateral to the border of the pedicle for adequate medial convergence especially in lumbar vertebrae to create the right trajectory for placement of pedicle screws and to avoid superior facet joint violation during insertion. The incision should be sufficient enough to accommodate the screw extender system. A transpedicular channel is created using the Jamshidi needle under AP and lateral 2D fluoroscopic guidance starting from 2 o'clock position of the pedicle. The needle is advanced using a mallet into the pedicle approximately $25-30 \mathrm{~mm}$ into the bone with care taken not to advance across the medial border of pedicle in 9 o'clock position in AP view (Fig. 1(C). Guide wires are subsequently inserted into the pedicles through the needles and confirmed fluoroscopically (Fig. 1D). The serial dilators were used to dilate over the guide wires and the pedicles were tapped using a cannulated tap. Screws were placed with corresponding screw extenders and the rod was introduced with a device through same or a separate proximal stab incision. After placement of locking-cap screws through the screw extenders and with application of compression, the screws were torqued and the screw extenders were removed ${ }^{10)}$. All screws were put by single surgeon standing on right side of patient so both right and left side screws were inserted from right side of the patient. The basic steps of MIS-TLIF procedure was followed
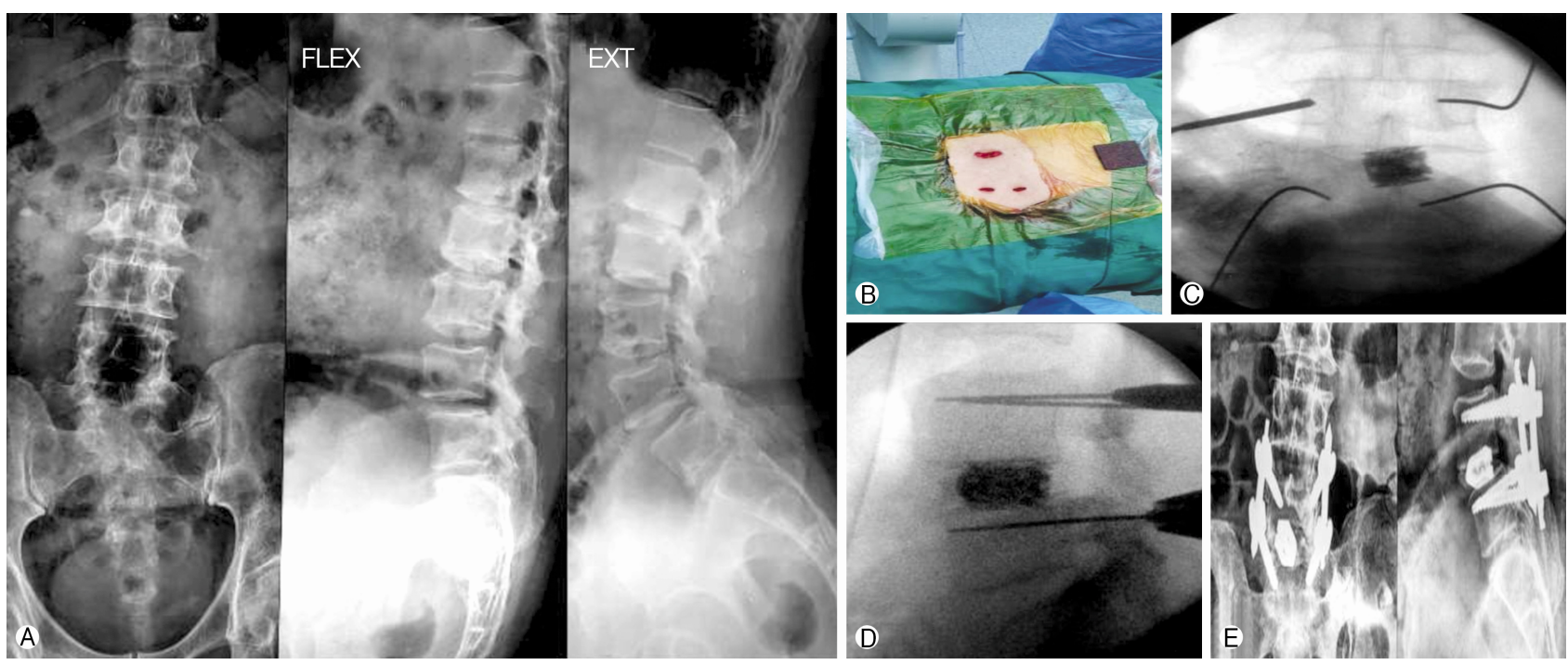

Fig. 1. (A) Minimally invasive transforaminal lumbar interbody fusion preoperative X-ray, (B) intraoperative photograph showing paramedian skin incisions, (C) intraoperative 2D fluoroscopy Anteroposterior image, (D) intraoperative 2D fluoroscopy lateral image, (E) Minimally invasive transforaminal lumbar interbody fusion postoperative $\mathrm{X}$-ray. 
for neural decompression and fusion using the tubular system.

\section{Evaluation Method}

Postoperative routine AP and lateral plain radiographs were performed within 48 hours after surgery (Fig. 1(E)). CT scan is more accurate than standard radiographs for evaluating the accuracy of pedicle screw placement revealing 10 times more medial wall perforations. However, the criteria for accuracy vary in the literature, ranging from encroachment of the pedicle wall to millimetres of breach ${ }^{15,16,28,33)}$. The CT scan with $2 \mathrm{~mm}$ axial slices with sagittal and axial reconstructive images adjusted parallel to the pedicle screws was used to assess pedicle screw perforation in all patients that is performed within three weeks of surgery. A quick MRI scan was considered mandatory in cases of worsening postoperative radiculopathy or neurological deficits. Two of the authors who were unaware of the surgical procedures reviewed the CT images independently to evaluate the perforation rate and other indices on both sides: (1) Direction of perforation (medial/lateral/superior/inferior/anterior) (2) Perforation rate (number of perforation/total number of screws placed) (3) Accuracy of pedicle screw placement and percentage of accurately placed screws (4) Perforation grading as per Mirza et al. ${ }^{19)}$ (Table 2) and (5) Critical/Non-critical perforation (pedicle Screw penetration $>2 \mathrm{~mm}$ was taken as critical because it could lead to neurovasucular and visceral injury. Screw penetration $<2 \mathrm{~mm}$ that remains within safe zone was classified as non-critical). So grade 2 and grade 3 are critical perforation group. The clinical outcome in the form of VAS and ODI were evaluated postoperatively at three weeks postoperatively in patients with and without perforations.

\section{Statistical Analysis}

The statistical analysis was done with student $t$-test using SPSS 20.0 software and Microsoft excels statistical function. P-value $<0.005$ was considered as significant value. Post operative $\mathrm{CT}$ scan analysis was done with the help of DICOM software viewer.

\section{RESULTS}

The study included 300 consecutive patients (168 females and 132 males) with symptomatic (mechanical and radicular) lumbar or lumbosacral degenerative spondylolisthesis grade one who underwent MIS-TLIF. The mean age was $55.56 \pm 9.8$ years with a male to female ratio of $132 / 168$ (Table 1). The overall rate of pedicle screw perforation was $5 \%(60 / 1,200)$ in single level lower lumbar MIS-TLIF. The CT scans showed 42 (3.5\%) screws with grade 1 perforation and $18(1.5 \%)$ screws with grade 2 and no screw in grade 3 perforations (Table 2) (Fig. 2). The pedicle screw placement at L5 had a higher incidence of pedi-

Table 1. Patient demographic and surgical data

\begin{tabular}{lc}
\hline \hline Variable & value (N=300) \\
\hline Age (mean) & $55.56 \pm 9.8$ \\
Sex & 132 \\
$\quad$ Male & 168 \\
$\quad$ Female & \\
Levels & 168 \\
L4-L5 & 132 \\
L5-S1 & 1,200 \\
Total number of screws & $60(5 \%)$ \\
Perforation rate & \\
Grading of pedicle screw perforation & $1,140(95 \%)$ \\
Grade 0 & $42(3.5 \%)$ \\
Grade 1 & $18(1.5 \%)$ \\
Grade 2 & 0 \\
Grade 3 & $18(1.5 \%)$ \\
Critical perforation & $42(3.5 \%)$ \\
Non critical perforation & $145 \pm 11$ \\
Mean surgical time (minutes) & $110 \pm 8.5$ \\
Mean surgical blood loss (mL) &
\end{tabular}
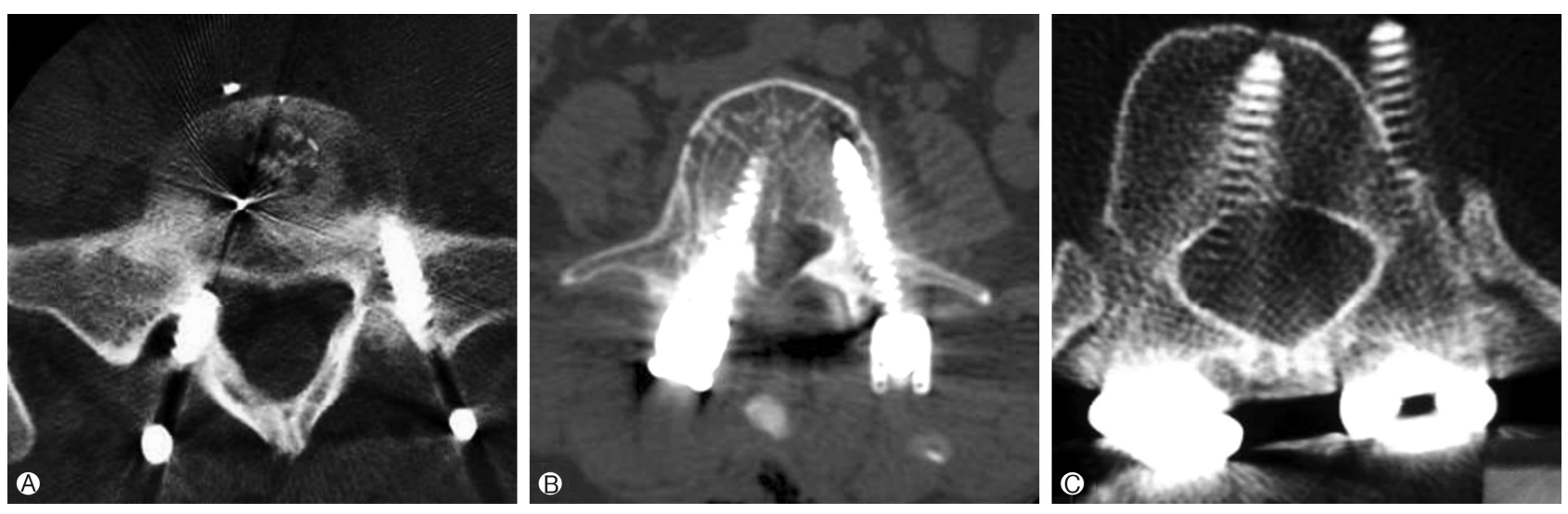

Fig. 2. Different grades of pedicular wall perforation. (A) Grade 1, (B) Grade 2, (C) Grade 3. 
cle perforation in comparison to $L 4$ and $\mathrm{S} 1$ with $53.3 \%$ at $\mathrm{L} 5$ level and $13.4 \%$ at $L 4$ and $33.3 \%$ at S1 level (Table 3). Moreover, on comparing direction of breach, there was 5 pedicle screw showed breach in superior and 1 in inferior pedicle wall and no breach in anterior wall of the vertebral body. While comparing lateral and medial wall breach, 50\% screws showed breach on lateral wall while $40 \%$ screws showed breach on medial pedicle wall. On further evaluation of lateral wall breach rate, $60 \%$ breach occurred at L5 level and 26\% at S1 level and 14\% at $L 4$ level. While medial wall breach rate is $15 \%$ at $L 4,50 \%$ occurred at L5 level and 35\% at S1 level It has also been seen that out of total 60 pedicle screw perforation about 37 (61\%) perforation occurred on right side and maximum 20 (33.3\%)

Table 2. Mirza et al. classification for pedicle perforation

\begin{tabular}{cc}
\hline \hline Grades & Degree of cortical violation $(\mathrm{mm})$ \\
\hline 0 & $<0$ \\
1 & $0-2$ \\
2 & $2-4$ \\
3 & $>4$ \\
\hline
\end{tabular}

Table 3. Pedicle perforation rate

\begin{tabular}{cc}
\hline \hline Variable & Incidence (Out of 1,200) \\
\hline Pedicle level & \\
L4 Right & 05 \\
Left & 03 \\
L5 Right & 20 \\
Left & 12 \\
S1 Right & 12 \\
$\quad$ Left & 08 \\
Perforation direction & \\
Medial & 24 \\
Lateral & 30 \\
Superior & 05 \\
Inferior & 01 \\
Anterior & 00 \\
Body mass index $\left(\mathrm{kg} / \mathrm{m}^{2}\right)$ & \\
$<30$ & 18 \\
$>30$ & 42 \\
Depth of spine $(\mathrm{mm})$ & \\
$<50$ & 21 \\
$>50$ & 39
\end{tabular}

particularly at the level of L5. Total number of critical breach in this study is $18(30 \%)$ but all them were asymptomatic or with no neurological injury. The best time to revise a nonoptimally positioned screw is in the primary surgery howbeit in this retrospective study, only one screw revision immediately after primary surgery was necessary because of a medial breach in an moderately osteoporotic patient although removing malpositioned pedicles screws may cause catastrophic spinal cord injury and/or dural tear with CSF leakage. Screw loosening and failure of fusion construct was not observed postoperatively in 2 yrs followup. The mean surgical time was $145 \pm 11$ minutes and mean Blood loss was $110 \pm 8.5 \mathrm{~mL}$. There were no intra operative CSF leaks and no post operative neurological injury arousing of misplaced screws in any patients. Significant improvement was noted in clinical outcome in the form of VAS, $(3.023 \pm 0.61)$ in perforation group and $(3.178 \pm 0.56)$ ( $p$-value $<0.0001)$ in non perforation group and in ODI, (28.14 \pm 1.93$)$ in perforation group and $(28.78 \pm 5.99)$ ( $p$-value $<0.0001$ ) in non perforation group, postoperatively (Table 4). Perforation rate in patients with BMI $>30 \mathrm{~kg} / \mathrm{m}^{2}$ was significantly higher than those with $\mathrm{BMl}<30 \mathrm{~kg} / \mathrm{m}^{2}$. The increased depth of the spine $(>50 \mathrm{~mm}$ ) was also significantly associated with the higher incidence of perforation rate.

\section{DISCUSSION}

MIS-TLIF has been introduced with the goals of smaller operative wounds, reduced trauma to paraspinal muscles, and quicker postoperative recovery, all of which may in turn result in minimal blood loss, decreased hospital stay, and decreased rates of surgical site infection ${ }^{23}$. The accuracy, safety, and perforation of pedicle screws inserted with the conventional open method has been widely studied with perforation rates ranging from $1.5 \%$ to $25 \%$ in clinical studies ${ }^{14)}$. Although 2D Fluoroscopic-guided percutaneous pedicle screw placement has been proved accurate and safe in previous literature however there had a large variation in the published data on perforation rates of this technique. Moreover misplaced screws is a deviation from the perfect screw position and does not necessarily equate with negative outcomes for the patient ${ }^{7}$. The technique of percutaneous pedicle screw placement under 2D fluoroscopic guidance markedly minimizes inaccurate screw placement to increase its reliability but intraoperatively it is very essential to continuously monitor the position of pedicle screws and have full control of the guide wire from insertion to removal with special care taken to avoid advancement of the guide wire, while introducing the tap and screws or backward dislodgment, while removing the tap because inaccurate screw placement can result

Table 4. Clinical outcome: the perforated group and non-perforated group

\begin{tabular}{lccc}
\hline \hline Clinical score & Perforation group & Non perforation group & p-value \\
\hline Mean preoperative VAS & $8.001 \pm 0.28$ & $8.101 \pm 0.49$ & $<0.0001$ \\
Mean postoperative VAS & $3.023 \pm 0.61$ & $3.178 \pm 0.56$ & $<0.0001$ \\
Mean preoperative ODI & $58.29 \pm 3.17$ & $59.71 \pm 4.39$ & $<0.0001$ \\
Mean postoperative ODI & $28.14 \pm 1.93$ & $28.78 \pm 5.99$ & $<0.0001$ \\
\hline
\end{tabular}


in serious neurologic or vascular, visceral injuries. 2D Fluoroscopic-guided percutaneous pedicle screw placement technique has variable pedicle perforation rate in lumbosacral region in the previous studies ranging from $2.6 \%$ to $14.3 \% \%^{1,26)}$ and the overall rate of pedicle screw perforation is $5 \%(60 / 1,200)$ in this study and that is almost comparable to above mentioned study. Oh et al. ${ }^{21)}$ reported a higher perforation rate in $\mathrm{L} 4$ and lower perforation rate in $S 1$ when compared to $L 5$, possibly explained by incremental pedicular size caudally but incidentally in this study the lowest perforation rates were found at L4 and S1 equally. A study has shown that most percutaneous pedicle perforations were directed laterally $(39.8 \%)$, followed by medially (25.7\%) and majority of the perforations were grade $1(8.4 \%)$ with no screw-related complications ${ }^{18)}$. Our study results also show most perforations were directed laterally $(30,50 \%)$, followed by medially $(24,40 \%)$ with none of the perforations led to any screw-related complications. It is observed that screws percentage fully contained in the pedicle ranging from $69-94 \%$ using free-hand technique, from 28 to $85 \%$ in $2 \mathrm{D}$ fluoroscopy, from 89 to $100 \%$ with the help of CT guided navigation and $81-92 \%$ using 2D fluoroscopy-based navigation ${ }^{6}$. The above study observes that medial wall breach is more commonly observed in free-hand technique, whereas lateral wall breach is in 2D fluoroscopy guided navigation technique. This present study also observed $95 \%$ screws fully contained in the pedicle and lateral pedicle wall breach more commonly using $2 \mathrm{D}$ fluoroscopy although lateral pedicle wall breach is less likely to associated with neurological injury. Historically, the primary safety concerns associated with pedicle screw placement have been complications related to neurologic or vascular injuries ${ }^{177}$. Anteriorly misplaced screws can have potentially devastating complications due to penetration of vascular, visceral, sympathetic and neural structures by the screws ${ }^{34}$. Neural injuries were observed in association with medial or inferior pedicular wall breach, although the severity of such injuries has not been clearly demonstrated ${ }^{4,32)}$. Complications related to screw malpositioning were not observed in this study at final follow up. Chiu et al. ${ }^{2)}$ showed that greater caution must be taken during the insertion of $\mathrm{L} 5$ and $\mathrm{S} 1$ percutaneous pedicle screws because of greater angulation of pedicles of these segments, the variable anatomy in their vertebral bodies and the morphology of the spinal canal at this location. Several reports had documented screw perforations rates from 3.0\% to 7.3\% with computer-assisted percutaneous screws placement ${ }^{24,35)}$. Similarly in this study pedicle perforation rate is higher at L5 level particularly on right side could possibly be due to surgeon's position i.e. on the right side of the patient while putting screws on both sides, variable anatomy of L5 pedicle required more mediolateral retraction and valid area of the pedicle screw trajectory of $L 5$ was not as broad as expected. Computer-assisted navigation percutaneous pedicle screw placement is a novel alternative to fluoroscopic-guided percutaneous pedicle screw placement. A study comparing percutaneous pedicle screw perforation rate with Computer-assisted navigation technique is $0 \%$ while in fluoroscopic-guided technique shows $3.3 \%$ pedicle perforation rate the difference of which is statistically significant $(p<0.05 \text {; chi-test })^{20}$. Despite the disadvantages of more radiation exposure, 2D fluoroscopic-guided screws placement may still remain as the most feasible technique in many centers due to the cost, availability, ease of use and need of extra time for registration of anatomic landmarks in computer assisted navigation devices. To increase the accuracy and precision of percutaneous pedicle screw insertion technique without use of a navigation system we need to evaluate the causes of pedicle screw misplacement. Several authors have reported that obesity is a significant risk factor for pedicle screw misplacement ${ }^{14,36)}$. Intraoperative 2D fluoroscopic identification of anatomical landmarks are frequently blurred in high BMl patients, moreover obesity bring about excessive bleeding and also muscle retraction is more difficult to perform. Therefore, we advice that surgeons should pay more attention to inserting pedicle screws in bulky patients. According to Kim et al. fluoroscopic images are often blurred in areas where the tissue is bulky particularly multifidus muscle ${ }^{14}$. . Rosen et al. has shown obesity is not a risk factor for complications during MIS-TLIF ${ }^{25}$. However accurate insertion of pedicle screw is affected by obesity in this study, with perforation rate in patients with BMl $>30 \mathrm{~kg} / \mathrm{m}^{2}$ was significantly higher than those with $\mathrm{BMl}<30 \mathrm{~kg} / \mathrm{m}^{2}$. Another important factor for screw misplacement observed in this study was pedicle convergent angle in mediolateral or axial direction. In this study most of pedicle perforation occurred in lateral direction, means more discrepancy between the pedicle medial convergent angle and the screw trajectory angle was found, i.e. more medial convergent angle should be given. So $2 \mathrm{D}$ fluoroscopy guided percutaneous pedicle screws placement with correct axial trajectory in True anteroposterior view in MIS-TLIF helps in reducing screw related complications and revision surgery. Other parameters like age and gender did not affect the pedicle screw perforation rate and final outcome in this retrospective study. MIS-TLIF in particular, can result in increased 2D fluoroscopy exposure times ${ }^{29}$. Bearing in mind that surgeon and staff are exposed to radiation during their daily routine, one has to find solutions to reduce the occupational radiation exposure which also makes using $2 \mathrm{D}$ fluoroscopy safe and reliable in minimal invasive techniques. Firstly Radiation protection principles like wearing adequate lead equipment (including thyroid shield and lead glass goggles), having trained technicians and keeping a distance from the radiation source are well known measures. Secondly It is important to point out that it is not only the surgical technique but the fluoroscopic techniques like application of pulsed fluoroscopy and digital spot image helps to minimize radiation exposure ${ }^{3)}$.

\section{Tips for safe pedicle screws placement:}

1. A more lateral skin incision in lumbar vertebrae will create the right trajectory for instrumentation placement in line with long axis of the pedicle.

2. Vigilant jamshidi needle management is critical in preventing inadvertent guide wire advancement and pullout. The tap and screw should typically follow the guide wire path 
which could otherwise lead to misplaced screw insertion.

3. The jamshidi needle tip might slip away from the entry point when the needle direction is usually not perpendicular to the cortical bone surface at the entry point so surgeon should make a pilot hole before entering into pedicle.

4. To save time and reduce radiation exposure, we prefer to cannulate all pedicles, at least on each side, using AP projection with confirmation provided using lateral projection. Guide wires are then placed and advanced using the same lateral projection.

While looking at limitations in this study few of them are following. The small sample size is one of the limitation. A large cohort study is required to establish the feasibility and effectiveness of 2D fluoroscopic assisted percutaneous pedicles screw insertion in MIS-TLIF. Secondly, this was a single institute, single surgeon-based study, so result of our study cannot be generalized as it may differ with the experience of the surgeon. The assessment of perforation rate based on CT grading system used in our study is not validated as it is only descriptive classification. Thirdly, the lack of comparison with other assisted techniques for screw insertion like open procedure, 3D fluoroscopy, O-arm and navigation could be one of the limitations. Fourth, the complications that were to be recorded in this study were complications directly caused by perforated screws not other perioperative or intraoperative complications. Inspite of above limitations, properly pursuing technique of percutaneous pedicle screw placement is shown to achieve pedicle perforation rate comparable to that is witnessed using navigation guided techniques.

\section{CONCLUSION}

This study showed overall pedicle perforation rate of $5 \%$ $(60 / 1,200)$ with 2D Fluoroscopy guided lower lumbar single level MIS-TLIF for grade 1 degenerative spondylolisthesis including grade 1 perforations are 3.5\% and grade 2 perforation are 1.5\%. While most Perforations are non-critical and lateral. 2D Fluoroscopy guided percutaneous pedicle screws placement with appropriate technique in MIS-TLIF is an acceptable and reliable procedure with low rates of screw related complications and revisions. However this technique is associated with initial learning curve and technical skills that can be gained by enough experience while role of physical factors like high BMI, depth of spine and anatomical variations in avoiding pedicle screw misplacement cannot be ignored. The results of this study needs further validation through large multi-centre and randomised studies that can evaluate feasibility and accuracy of 2D fluoroscopy guided MIS-TLIF.

\section{REFERENCES}

1. Mark J Winder, Paul M Gilhooly: Accuracy of minimally invasive percutaneous thoracolumbar pedicle screws using 2D fluoro- scopy: A retrospective review through 3D CT analysis. Journal of Spine Surgery 3(2):193-203, 2017

2. Chiu CK, Kwan MK, Chan CY, et al: The accuracy and safety of fluoroscopically guided percutaneous pedicle screws in the lumbosacral junction and the lumbar spine: A review of 880 screws. Bone Joint J 97-B(8):1111-1117, 2015

3. Clark JC, Jasmer G, Marciano FF, Tumialán LM: Minimally invasive transforaminal lumbar interbody fusions and fluoroscopy: A low-dose protocol to minimize ionizing radiation. Neurosurgical Focus 35(2):E8, 2013

4. Foley KT, Gupta SK: Percutaneous pedicle screw fixation of the lumbar spine: Preliminary clinical results. J Neurosurg 97(1 Suppl):7-12, 2002; PMID: 12120655.

5. Fan S, Hu Z, Zhao F, Zhao X, Huang Y, Fang X: Multifidus muscle changes and clinical effects of one-level posterior lumbar interbody fusion: minimally invasive procedure versus conventional open approach. Eur Spine J 19:316-324, 2010

6. Gelalis ID, Paschos NK, Pakos EE, et al: Accuracy of pedicle screw placement: A systematic review of prospective in vivo studies comparing free hand, fluoroscopy guidance and navigation techniques. Eur Spine J 21:247, 2012; doi.org/10.1007/s00586-011-2011

7. Gertzbein SD, Robbins SE: Accuracy of pedicular screw placement in vivo. Spine (Phila 1976) 15:11-14, 1990 [PubMed] [Google Scholar]

8. Hsieh PC, Koski TR, Sciubba DM, et al: Maximizing the potential of minimally invasive spine surgery in complex spinal disorders. Neurosurgery Focus 25:E19, 2008

9. Hyun SJ, Kim YB, and Kim YS, et al: Postoperative changes in paraspinal muscle volume: Comparison between paramedian interfascial and midline approaches for lumbar fusion. J Korean Med Sci 22:646-651, 2007

10. Jones-Quaidoo SM, Djurasovic M, Owens RK 2nd, Carreon LY: Superior articulating facet violation: percutaneous versus open techniques. J Neurosurg Spine 18:593-597, 2013

11. Jorge Torres, Andrew R James, et al: Screw placement accuracy for minimally invasive transforaminal lumbar interbody fusion surgery: A study on 3-D neuronavigation-guided surgery. Global Spine J 2(3):143-152, 2012; doi:10.1055/s-0032-1326949.

12. Kawaguchi Y, Yabuki S, Styf J, et al: Back muscle injury after posterior lumbar spine surgery. Topographic evaluation of intramuscular pressure and blood flow in the porcine back muscle during surgery. Spine 21:2683-2688, 1996

13. Kim DY, Lee SH, Chung SK, Lee HY: Comparison of multifidus muscle atrophy and trunk extension muscle strength: Percutaneous versus open pedicle screw fixation. Spine 30:123-129, 2005

14. Kim MC, Chung HT, Cho JL, Kim DJ, Chung NS: Factors affecting the accurate placement of percutaneous pedicle screws during minimally invasive transforaminal lumbar interbody fusion. Eur Spine J 20:1635-1643, 2011; doi.org/10.1007/s00586-011-1892-5.

15. Kim YJ, Lenke LG: Thoracic pedicle screw placement: freehand technique. Neurol India 53:512-519, 2005 [PubMed] [Google Scholar]

16. Laine T, Lund T, Ylikoski M, Lohikoski J, Schlenzka D: Accuracy of pedicle screw insertion with and without computer assistance: a randomised controlled clinical study in 100 consecutive patients. Eur Spine J 9:235-240, 2000 [PMC free article] [PubMed] [Google Scholar]. 
17. Lehman RA Jr, Lenke LG, Keeler KA, Kim YJ, Cheh G: Computed tomography evaluation of pedicle screws placed in the pediatric deformed spine over an 8-year period. Spine (Phila Pa 1976) 32:2679-2684, 2007; PMID: 18007244.

18. McGirt MJ, Parker SL, Lerner J, Engelhart L, Knight T, Wang MY: Comparative analysis of perioperative surgical site infection after minimally invasive versus open posterior/transforaminal lumbar interbody fusion: Analysis of hospital billing and discharge data from 5,170 patients. J Neurosurg Spine 14(6):771778, 2011 [PubMed] [Google Scholar].

19. Mirza SK, Wiggins GC, Kuntz C, 4th, et al: Accuracy of thoracic vertebral body screw placement using standard fluoroscopy, fluoroscopic image guidance, and computed tomographic image guidance: A cadaver study. Spine (Phila Pa 1976) 28:402-413, 2003; [PubMed] [Google Scholar].

20. Nakashima, H, Sato, K, Ando, T: Comparison of the percutaneous screw placement precision of isocentric C-arm 3-dimensional fluoroscopy-navigated pedicle screw implantation and conventional fluoroscopy method with minimally invasive surgery. J Spinal Disord Tech 22(7):468-472, 2009; [Google Scholar] [Crossref] [Medline]

21. Oh HS, Kim JS, Lee SH, et al: Comparison between the accuracy of percutaneous and open pedicle screw fixations in lumbosacral fusion. Spine J 13(12):1751-1757, 2013

22. O’Toole JE, Eichholz KM, Fessler RG: Minimally invasive far lateral micro endoscopic discectomy for extraforaminal disc herniation at the lumbosacral junction: Cadaveric dissection and technical case report. Spine J 7:414-421, 2007

23. Parker SL, Adogwa O, Witham TF, Aaronson OS, Cheng J, McGirt MJ: Post-operative infection after minimally invasive versus open transforaminal lumbar interbody fusion (TLIF): Literature review and cost analysis. Minim Invasive Neurosurg 54(1): 33-37, 2011; [PubMed] [Google Scholar].

24. Raley DA, Mobbs RJ: Retrospective computed tomography scan analysis of percutaneously inserted pedicle screws for posterior transpedicular stabilization of the thoracic and lumbar spine: Accuracy and complication rates. Spine 37:1092-1100, 2012

25. Rosen DS, Ferguson SD, Ogden AT, Huo D, Fessler RG: Obesity and self-reported outcome after minimally invasive lumbar spinal fusion surgery. Neurosurgery 63:956-960, 2008; doi: 10.1227/01.NEU.0000313626.23194.3F. [PubMed] [CrossRef] [Google Scholar].

26. Schizas C, Tzinieris N, Tsiridis E, and Kosmopoulos V: Minimally invasive versus open transforaminal lumbar interbody fusion: evaluating initial experience. Int Orthop 33(6):1683-1688, 2009; [PMC free article] [PubMed] [Google Scholar].

27. Sihvonen T, Herno A, Paljärvi L, Airaksinen O, Partanen J, Tapaninaho A: Local denervation atrophy of paraspinal muscles in postoperative failed back syndrome. Spine 18:575-581, 1993.

28. Smith ZA, Sugimoto K, Lawton CD, et al: Incidence of lumbar spine pedicle breach following percutaneous screw fixation: A radiographic evaluation of 601 screws in 151 patients. J Spinal Disord Tech 27(7):358-363, 2014; doi:10.1097/BSD. 0b013e31826226cb.

29. Tian N-F, Wu Y-S, Zhang X-L, Xu H-Z, Chi Y-L, Mao F-M: Minimally invasive versus open transforaminal lumbar interbody fusion: a meta-analysis based on the current evidence. Eur Spine J 22:1741-1749, 2013; doi:10.1007/s00586-013-2747-z. [PMC free article] [PubMed] [CrossRef] [Google Scholar]

30. Tredway TL, Santiago P, Hrubes MR, Song JK, Christie SD, Fessler RG: Minimally invasive resection of intradural-extramedullary spinal neoplasms. Neurosurgery 58(1, Suppl):ONS52ONS58, 2006; discussion:ONS5-ONS58.

31. Weber BR, Grob D, Dvorák J, Müntener M: Posterior surgical approach to the lumbar spine and its effect on the multifidus muscle. Spine 22:1765-1772, 1997

32. Weinstein JN, Rydevik BL, Rauschning W: Anatomic and technical considerations of pedicle screw fixation. Clin OrthopRelat Res 284:34-46, 1992

33. Weinstein JN, Spratt KF, Spengler D, Brick C, Reid S: Spinal pedicle fixation: Reliability and validity of roentgenogram-based assessment and surgical factors on successful screw placement. Spine (Phila Pa 1976) 13:1012-1018, 1988; [PubMed] [Google Scholar]

34. Whitecloud TS, Skalley TC, Cook SD, Morgan EL: Roentgenographic measurement of pedicle screw penetration. Clin Orthop Relat Res 245:57-68, 1989

35. Yang, BP, Wahl, MM, Idler, CS: Percutaneous lumbar pedicle screw placement aided by computer-assisted fluoroscopy-based navigation: Perioperative results of a prospective, comparative, multicenter study. Spine 37(24):2055-2060, 2012; [Google Scholar] [Crossref] [Medline] [ISI]

36. Yoshii T, Hirai T, Yamada T, Sumiya S, Mastumoto R, Kato T, Enomoto M, Inose H, Kawabata S, Shinomiya K, Okawa A: Lumbosacral pedicle screw placement using a fluoroscopic pedicle axis view and a cannulated tapping device. J Orthop Surg Res 10:79, 2015; doi.org/10.1186/s13018-015-0225-5. 